\title{
Experiência das Pessoas com Deficiência nos Serviços de Saúde: Contribuição para a Formação Profissional
}

\author{
Resende, Adara Cabral; Nóbrega, Simone da; Moreira, Tomaz \\ Universidade Federal do Rio Grande do Norte — adaracabral@hotmail.com
}

Introdução: a política nacional de saúde da Pessoa com Deficiência (PCD), vigente há mais de dez anos, preconiza uma atenção integral à saúde dessas pessoas, devendo ser disponibilizada não apenas uma assistência específica a sua condição, mas também a agravos comuns a qualquer pessoa. no entanto, a formação dos profissionais de saúde, em geral, não contempla a pessoa com deficiência, não reconhecendo as particularidades do seu corpo, como também negligencia aspectos relevantes para o atendimento integral a essas pessoas. Objetivo: conhecer a experiência das PCD nos serviços de saúde, de modo a contribuir para uma formação profissional integral. Métodos: estudo de natureza qualitativa, descritiva e analítica fundamentado no método Fenomenológico, que objetiva alcançar o sentido da experiência, ou seja, o que a experiência vivida significa para as pessoas. a técnica utilizada foi o grupo focal com a participação de 6 sujeitos ( 3 cegos, 2 surdos, 1 intérprete de libras), além de um moderador e um observador. o roteiro de discussão foi focado na acessibilidade ao serviço de saúde e na relação médico-paciente. Resultados: a análise dos dados aponta que os entrevistados não se sentiram acolhidos pelos profissionais de saúde, no sentindo de terem sua condição reconhecida e valorizada. Eles apontam a falta de informação dos profissionais acerca das especificidades das suas condições de saúde, como também a não sensibilidade às suas necessidades nessa área, como pontos importantes na origem da precariedade do serviço de saúde para pessoas com deficiência. Afirmaram ainda que não se sentiram compreendidos, o que comprometeu a relação médico-paciente. Os entrevistados surdos, por exemplo, expressam dificuldades de comunicação com o profissional de saúde, sendo necessário que esteja sempre presentes nas consultas um familiar ou intérprete ferindo, dessa forma, a autonomia do paciente. Os participantes deste estudo sugeriram a implementação de disciplinas nos cursos de saúde que abranjam a inclusão social de pessoas com deficiência, focando em especial a acessibilidade à saúde de uma forma humanizada. Conclusão: o processo de humanização é uma meta atual e fundamental no sistema de saúde brasileiro, porém só poderá ser completa se for consolidada de uma forma inclusiva. Sendo assim, fica evidente a necessidade de que os novos alunos ingressantes nos cursos da saúde e os profissionais já formados nessa área vivenciem práticas específicas relacionadas à cultura da inclusão. Dessa forma, os profissionais se tornarão aptos para assistir a sociedade como um todo, através de um conhecimento e empatia adquiridos na sua formação profissional.

Resende, Adara Cabral; Nóbrega, Simone da; Moreira, Tomaz. Experiência das Pessoas com Deficiência nos Serviços de Saúde: Contribuição para a Formação Profissional. In: Anais do Congresso Internacional de Humanidades \& Humanização em Saúde [= Blucher Medical Proceedings, num.2, vol.1]. São Paulo: Editora Blucher, 2014. ISSN 2357-7282

DOI 10.5151/medpro-cihhs-10308 